\title{
EXTRACTION OF THYMOL FROM DIFFERENT VARIETIES OF THYME PLANTS USING GREEN SOLVENTS
}

\author{
Ivan Angelov ${ }^{1}$, David Villanueva Bermejo ${ }^{2}$, Roumiana P. Stateva ${ }^{1}$, Guillermo Reglero ${ }^{2}$, Elena Ibañez ${ }^{2}$ and \\ Tiziana Fornari ${ }^{2}$ \\ ${ }^{1}$ Institute of Chemical Engineering \\ Bulgarian Academy of Sciences \\ 1113 Sofia, Bulgaria \\ ${ }^{2}$ Instituto de Investigación en Ciencias de la Alimentación CIAL (CSIC-UAM). CEI UAM + CSIC. C/Nicolás Cabrera 9 \\ Universidad Autónoma de Madrid \\ 28049 Madrid, España \\ E-mail: david.villanueva@uam.es
}

\begin{abstract}
Thyme is a Labiatae plant which essential oil has demonstrated antiseptic and antispasmodic, properties [6, 7]. Thymol (2-isopropyl-5-methylphenol) is the main monoterpene phenol, isomeric with carvacrol, found in thyme essential oil. These compounds have shown antiinflamatory, immunomodulatory, antioxidant, antibacterial and antifungal properties. [8,9]

In this work, the potential use of different green solvents, namely ethanol, limonene and ethyl lactate to extract thymol from thyme plants is studied. Ethyl lactate and limonene are agrochemical solvents, easily biodegradable, with polarities in the range of acetonitrile and hexane, respectively. Both solvents are recognized as GRAS (generally recognized as safe) and approved by the U.S. Food and Drug Administration as pharmaceutical and food additive. Further, high solubility of thymol in ethyl lactate has been recently determined and reported by the authors [30].

Pressurized liquid extraction (PLE) in an ASE 350 system using the three green liquid solvents at different extraction temperatures $\left(60{ }^{\circ} \mathrm{C}, 130{ }^{\circ} \mathrm{C}, 200{ }^{\circ} \mathrm{C}\right)$ was carried out employing Thymus vulgaris as model thyme variety. Then, the extraction of thymol from other thyme varieties (Thymus zygis and Thymus citriodorus) was studied. Extraction yield and thymol recovery obtained in the different extracts was quantified and compared. The three green solvents have shown good capacity to extract thymol from thyme plants.
\end{abstract}

Keywords: Pressurized Liquid Extraction (PLE), Thyme, Ethyl Lactate, Limonene, Thymol.

\section{Introduction}

In the European market there are a lot of products derived from natural plants, which are recognized to posses different biological properties, such as antioxidant, antiseptic, diuretic, stimulating the central nervous system, sedative, expectorant, digestive, etc. Some of these plants have been used in traditional medicine since ancient times and are available on market as infusions, tablets and/or extracts.

The genus Thymus (Lamiaceae family) is an aromatic plant that includes numerous species with quite different botanical characteristics and a broad chemical heterogeneity [1] and one of the most valued constituents of the herb (especially of the leaves) is the essential oil. Essential oil is formed by volatile aroma compounds and the main components are terpenes, sesquiterpenes and several oxygenated derivative compounds (alcohols, aldehydes, ketones, acids, phenols, ethers, esters, etc.) all of them responsible for the characteristic plant odor and flavor [2]. Thyme essential oil is appreciated for food flavoring [3] in cosmetic, perfumery [4] and in the pharmaceutical industries [5]. Among other properties, antimicrobial activity, antitussive, antispasmodic actions and antioxidative effects have been recognized as pharmacological actions $[6,7]$. Among the constituents of thymus essential oil, which contribute to its biological activities, are thymol 
and its isomer carvacrol.Thymol (2-isopropyl-5-methylphenol) is the main monoterpene phenol found in thyme essential oil. Thymol and carvacrol have shown antiinflamatory, immunomodulators, antioxidant, antibacterial and antifungal properties [8,9].The variety most studied is, indeed, Thymus vulgaris [10-12]. Yet, particularly attention is focused on Thymus zygis [13], a thyme variety widespread over Portugal and Spain and Thymus citriodorus, a plant cultivated in the Mediterranean region [14].

Essential oil of thyme herb has usually been obtained by either steam distillation or traditional liquid extraction methods such as Soxhlet extraction, maceration or extraction under reflux. Although these methods are relatively simple, they suffer from several shortcomings as a long extraction time and a relatively high solvent consumption. Pressurized liquid extraction (PLE), a relatively recent solvent extraction technique, could, in principle, eliminate some of the drawbacks of the classical solvent extraction methods. PLE is based on the use of solvents at temperatures above their normal boiling points and pressures enough to keep the extracting fluid in the liquid state during the whole extraction process. By applying these conditions, faster extraction processes result, in which, typically, higher extraction yields are obtained with lower volumes of organic solvents $[15,16]$.

Several works have been reported about PLE extraction of essential oils from some raw herbal materials [17-20], however, a few works have been reported about PLE extraction of essential oil from thymus. In this sense, hexane, dichloromethane, ethyl acetate and water have been used as extraction solvents of essential oil from thyme herb [21-23].

Ethyl lactate (ethyl 2-hydroxypropanoate) is an agrochemical and economically viable alternative to traditional liquid solvents: it is fully biodegradable, non-corrosive, non-carcinogenic and non-ozone depleting. It was self-affirmed as GRAS (generally recognized as safe) and due to its low toxicity, it was approved by the U.S. Food and Drug Administration (FDA) as pharmaceutical and food additive. These characteristics have increased the attention to the use of ethyl lactate as a green solvent for the food industry. Several reported potential applications are related to the extraction of carotenoids from different plant matrix [24, 25], with the fractionation of edible oil compounds (squalene and tocopherol) [26, 27], with the extraction of gamma-linnolenic acid from the microalgae Spirulina platensis [28], and with the extraction of caffeine from green coffee beans and green tea leaves [29]. In addition, high solubility of thymol in ethyl lactate at different temperatures has been reported by the authors in a recent contribution [30].

As ethyl lactate, D-limonene (1-methyl-4-(1-methylethenyl)-cyclohexene) is a non-toxic, non-corrosive, non-carcinogenic and fully biodegradable solvent and was approved by FDA as GRAS. This monoterpenic molecule is the major component of essential oils extracted from citrus peels and is a major by-product of the citrus fruits industry $[31,32]$. Therefore, this solvent has been found to be a valuable alternative to the petroleum solvents and, for this reason, D-limonene has been used to remove oil from rice brand [33] and olive seeds [31], and lycopene from tomato [34].

The aim of this work was to test the potential use of different green solvents, namely ethanol, limonene and ethyl lactate to extract thymol from thyme plants. Pressurized liquid extraction was accomplished in an Accelerated Solvent Extraction system ASE 350 using the three green liquid solvents at different extraction temperatures $\left(60{ }^{\circ} \mathrm{C}, 130{ }^{\circ} \mathrm{C}, 200{ }^{\circ} \mathrm{C}\right)$ and it was carried out employing Thymus vulgaris as model thyme variety. Then, the extraction of thymol from other thyme varieties (Thymus zygis and Thymus citriodorus) was explored. Extraction yield and thymol recovery obtained in the different extracts was quantified and compared.

\section{Material and methods}

\subsection{Chemicals}

Ethanol was HPLC grade from Panreac. Thymol standard ( $\geq 99 \%)$, limonene $(90 \%)$ and ethyl lactate $(\geq$ 98\%) was supplied from Sigma-Aldrich.

\subsection{Thyme leaves preparation}

The thyme samples (T. vulgaris, zygis and citriodorus) consisted of dried leaves obtained from a herbalist's producer (Murcia, Spain). The samples were ground in a cooled mill and particle of sizes smaller than $500 \mu \mathrm{m}$ were separated by using sieves and employed for the experiments. The whole sample was stored at $-20^{\circ} \mathrm{C}$ until use. 


\subsection{Pressurized Liquid Extraction (PLE)}

Thymol extractions were carried out in an Accelerated Solvent Extraction system ASE 350 from Dionex Corporation (Sunnyvale, CA, USA) equipped with a solvent controller unit. A scheme of the equipment is shown in Figure 1.

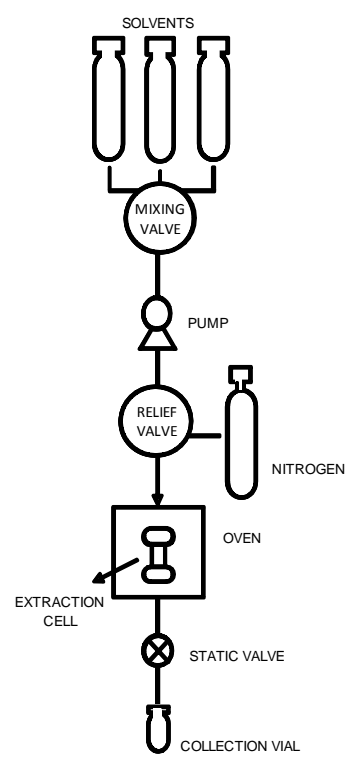

Figure 1. Scheme of ASE device employed in the present work.

The cells employed (10 ml capacity) were placed into an oven; each cell was filled with around $1 \mathrm{~g}$ of solid sample. After loading the sample into the extraction cell, the cell was filled with the corresponding solvent up to a pressure of $10 \mathrm{MPa}$ (which ensures the liquid state of the three solvents employed at the three studied temperatures) and was heated-up to the desired temperature. In order to prevent over-pressurization of the cell, a static valve pulses open and close automatically when the cell pressure exceeds the set point. The solvent that escapes during this venting is collected in the collection vial. Then, a static extraction continues, in which all system valves are closed. After extraction the cell was washed with the solvent and subsequently the solvent was purged from cell using $\mathrm{N}_{2}$ gas until complete depressurization was accomplished.

\subsection{Determination of thymol by GC/MS analysis}

The analyses of thyme extracts were carried out in Agilent 7890A System (Agilent Technologies. Santa Clara, California, USA) comprising a split/splitless injector, electronic pressure control, G4513A auto injector, a 5975C triple-axis mass spectrometer detector, and GC/MS Solution software. The column used was an Agilent HP-5MS capillary column $(30 \mathrm{~m} \times 0.25 \mathrm{~mm}$ i.d. and $0.25 \mu \mathrm{m}$ phase thickness $)$. The chromatographic method was as follows: oven temperature programming was $60^{\circ} \mathrm{C}$ isothermal for 4 min then increased to $106^{\circ} \mathrm{C}$ at $2.5{ }^{\circ} \mathrm{C} / \mathrm{min}$ and from $106^{\circ} \mathrm{C}$ to $130^{\circ} \mathrm{C}$ at $1{ }^{\circ} \mathrm{C} / \mathrm{min}$ and finally from $130{ }^{\circ} \mathrm{C}$ to $250{ }^{\circ} \mathrm{C}$ at $20^{\circ} \mathrm{C} / \mathrm{min}$ and this temperature was kept constant for $10 \mathrm{~min}$. Sample injections $(1 \mu \mathrm{L})$ were performed in split mode (1:10). Chromatography separation was carried out at constant pressure of $143.6 \mathrm{kPa}$ and Helium (99.996 mass \%) was used as a carrier gas. Injector temperature was $250{ }^{\circ} \mathrm{C}$ and mass spectrometer ion source and interface temperatures were $230^{\circ} \mathrm{C}$ and $280^{\circ} \mathrm{C}$ respectively. Mass spectrometer was used in total ion current (TIC) mode and samples were scanned from 40 to $500 \mathrm{amu}$. Thymol was identified by comparison with standard mass spectra and compared with the mass spectra from library Wiley 229.

\section{Results and discussion}

In Table 1, the influence of the extraction time (10 and $20 \mathrm{~min})$ on the extraction yield, the thymol concentration and the quantity of recovered thymol during the ASE extraction of Thymus vulgaris using ethyl lactate as solvent at $200{ }^{\circ} \mathrm{C}$ is shown. The values given in the table correspond to the average values resulted 
from duplicate experiments. Standard deviations are also given in the table. As it can be seen, the extraction yield obtained in $10 \mathrm{~min}$ represents $83 \%$ of the yield obtained in $20 \mathrm{~min}$. Further the recovery and concentration of thymol obtained in both experiments are very similar. Considering these results, 10 minutes were selected to study the effect of temperature on thymol recovery.

Table 1. Extraction yield ( $\mathrm{g}$ of extract / $\mathrm{g}$ of sample $\times 100)$, thymol concentration $(\mathrm{g}$ thymol / g extract $\times$ 100) and thymol recovery (mg of thymol / g of sample) obtained in the ASE of Thymus vulgaris L. using ethyl lactate at $200{ }^{\circ} \mathrm{C}$ and two different extraction times: 20 and 10 minutes.

\begin{tabular}{ccc}
\hline \multicolumn{2}{c}{ extraction time } & \\
& $10 \mathrm{~min}$ & $20 \mathrm{~min}$ \\
\hline Solvent: ethyl lactate & & \\
extraction yield $(\%)$ & $22.66 \pm 0.26$ & $27.29 \pm 0.90$ \\
thymol concentration $(\%)$ & $3.75 \pm 0.17$ & $3.25 \pm 0.03$ \\
thymol recovery & $8.50 \pm 0.28$ & $8.88 \pm 0.38$ \\
\hline
\end{tabular}

Results obtained from the extraction of thymol from Thymus vulgaris L. using the three different solvents, at $60{ }^{\circ} \mathrm{C}, 130{ }^{\circ} \mathrm{C}$ and $200{ }^{\circ} \mathrm{C}$ and in $10 \mathrm{~min}$ of extraction time, are shown in Table 2 . As it was expected, despite the used solvent, extraction yield increased with the temperature. On the other hand, ethyl lactate and limonene show very similar behavior: the thymol concentration decreased with temperature (see Figure 2) and only slight higher thymol recovery was obtained as increasing extraction temperature. It appears that higher extraction temperature results in a greater solubilization of compounds other than thymol. In the case of ethanol, the highest thymol concentration and recovery were observed at $130{ }^{\circ} \mathrm{C}$.

Also, it should be noted that the highest concentrations of thymol in the extracts were obtained with limonene, due to its physicochemical character (it is part of plant essential oils), followed by ethyl lactate.

Comparing the results obtained in this work with data reported in the literature [22, 23], it was possible to attain thymol recoveries higher than those obtained with traditional methods, such as Soxhlet $(\approx 6.8 \mathrm{mg} / \mathrm{g}$ of thymol recovery) and steam distillation $(\approx 8.2 \mathrm{mg} / \mathrm{g}$ of thymol recovery). The recovery was very close to the supercritical fluid extraction (SFE) recoveries $(\approx 10.1 \mathrm{mg} / \mathrm{g})$ [22]. In addition, by using these "green solvents" the thymol recovered was slightly lower than PLE extraction with "non-green solvents" like hexane $(\approx 10.7$ $\mathrm{mg} / \mathrm{g})$, ethyl acetate $(\approx 12.8 \mathrm{mg} / \mathrm{g})$ or dichloromethane $(\approx 12.2 \mathrm{mg} / \mathrm{g})$. On the other hand, thymol recoveries were higher than those obtained with subcritical water extraction $(\mathrm{SWE})(\approx 7 \mathrm{mg} / \mathrm{g})[22,23]$.

Table 2. Extraction yield ( $\mathrm{g}$ of extract / $\mathrm{g}$ of sample $\times 100)$, thymol concentration $(\mathrm{g}$ thymol $/ \mathrm{g}$ extract $\times$ 100) and thymol recovery (mg of thymol / g of sample) obtained in the ASE of Thymus vulgaris L. using ethyl lactate, ethanol and limonene.

\begin{tabular}{|c|c|c|c|}
\hline \multicolumn{4}{|c|}{ extraction temperature } \\
\hline & $60^{\circ} \mathrm{C}$ & $130^{\circ} \mathrm{C}$ & $200^{\circ} \mathrm{C}$ \\
\hline \multicolumn{4}{|l|}{ Solvent: ethyl lactate } \\
\hline extraction yield (\%) & $6.21 \pm 0.03$ & $8.02 \pm 0.30$ & $22.66 \pm 0.26$ \\
\hline thymol concentration $(\%)$ & $13.88 \pm 0.10$ & $11.78 \pm 0.43$ & $4.65 \pm 0.02$ \\
\hline thymol recovery (mg/g) & $8.62 \pm 0.03$ & $9.44 \pm 0.01$ & $10.53 \pm 0.16$ \\
\hline \multicolumn{4}{|l|}{ Solvent: ethanol } \\
\hline extraction yield (\%) & $10.55 \pm 1.97$ & $15.91 \pm 0.36$ & $21.84 \pm 2.41$ \\
\hline thymol concentration $(\%)$ & $6.59 \pm 0.89$ & $6.89 \pm 0.78$ & $4.88 \pm 0.67$ \\
\hline thymol recovery (mg/g) & $7.03 \pm 2.23$ & $10.98 \pm 1.49$ & $10.58 \pm 0.28$ \\
\hline \multicolumn{4}{|l|}{ Solvent: limonene } \\
\hline extraction yield $(\%)$ & $4.37 \pm 0.15$ & $7.16 \pm 0.54$ & $9.52 \pm 1.47$ \\
\hline thymol concentration $(\%)$ & $18.15 \pm 0.25$ & $12.59 \pm 0.49$ & $10.06 \pm 0.82$ \\
\hline thymol recovery (mg/g) & $7.93 \pm 0.39$ & $9.00 \pm 0.32$ & $9.52 \pm 0.70$ \\
\hline
\end{tabular}




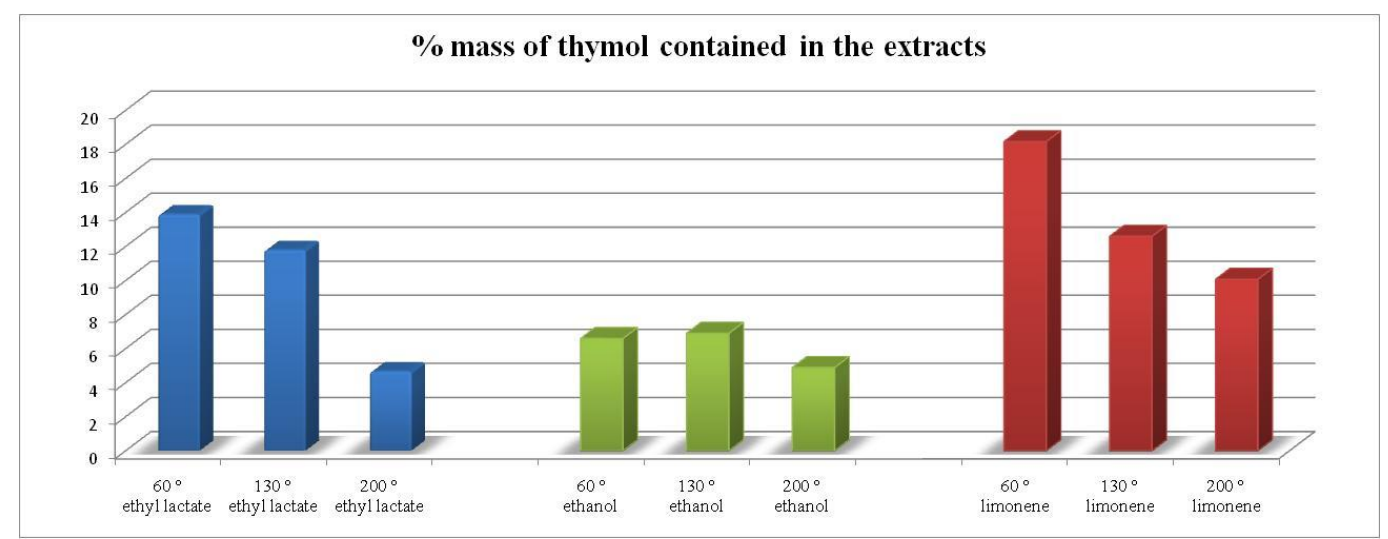

Figure 2. Concentration of thymol (\%) contained in the extracts

Results obtained from the extraction of thymol from the other varieties of thyme (namely Thymus zygis and Thymus citriodorus) using the three different solvents at $60{ }^{\circ} \mathrm{C}$ and 10 minutes of extraction time are shown in Table 3. In the case of Thymus zygis, the extraction yields obtained were higher than those obtained from Thymus vulgaris, especially in the case of ethyl lactate and limonene. Additionally, the thymol concentration obtained from Thymus zygis (especially in the case of ethyl lactate and limonene) was lower than in the case of Thymus vulgaris. Limonene was the solvent which removed the highest quantity of thymol from Thymus zygis, followed by ethyl lactate. In the case of Thymus citriodorus, no presence of thymol was detected despite the solvent employed. These results agree with some reports in the literature [35] in which significant lower amounts of thymol were detected in the essential oil of Thymus citriodorus in comparison with the Thymus zygis and Thymus vulgaris varieties.

Table 3. Extraction yield ( $\mathrm{g}$ of extract / $\mathrm{g}$ of sample $\times 100$ ), thymol concentration $(\mathrm{g}$ thymol $/ \mathrm{g}$ extract $\times$ 100) and thymol recovery (mg of thymol / $\mathrm{g}$ of sample) obtained in the ASE of Thymus zygis L. and Thymus citriodorus L. using ethyl lactate, ethanol and limonene at $60^{\circ} \mathrm{C}$.

\begin{tabular}{|c|c|c|}
\hline & Thymus zygis & Thymus citriodorus \\
\hline \multicolumn{3}{|l|}{ Solvent: ethyl lactate } \\
\hline extraction yield (\%) & $9.25 \pm 0.48$ & $8.32 \pm 0.21$ \\
\hline thymol concentration $(\%)$ & $6.77 \pm 0.10$ & - \\
\hline thymol recovery $(\mathrm{mg} / \mathrm{g})$ & $6.26 \pm 0.23$ & - \\
\hline \multicolumn{3}{|l|}{ Solvent: ethanol } \\
\hline extraction yield (\%) & $12.09 \pm 0.01$ & $11.10 \pm 1.56$ \\
\hline thymol concentration (\%) & $5.40 \pm 0.02$ & - \\
\hline thymol recovery (mg/g) & $6.53 \pm 0.02$ & - \\
\hline \multicolumn{3}{|l|}{ Solvent: limonene } \\
\hline extraction yield (\%) & $9.36 \pm 0.17$ & $11.35 \pm 0.17$ \\
\hline thymol concentration $(\%)$ & $8.96 \pm 0.13$ & - \\
\hline thymol recovery $(\mathrm{mg} / \mathrm{g})$ & $8.39 \pm 0.03$ & - \\
\hline
\end{tabular}

\section{Conclusion}

The potential use of three green solvent namely ethyl lactate, ethanol and limonene in the extraction of thymol from three varieties of Thymus (vulgaris, zygis and citriodorum) was presented in this work. PLE is a suitable technology and the three green solvents show good capacity to extract thymol from thyme plants, obtaining higher yields of thymol in shorter extraction times with lower consumption of extraction solvents than the traditional extraction method like steam distillation. 


\section{Acknowledgements}

The authors gratefully acknowledge the financial support from the Ministerio de Ciencia e Innovación (project 25506 FUN-C-FOOD) and Comunidad Autónoma de Madrid (ALIBIRD, project S-505/AGR-0153). D. Villanueva thanks for the JAE-pre fellowship given by Consejo Superior de Investigaciones Científicas (CSIC) of Spain.

\section{References}

[1] T. Adzet, R. Granger, J. Passet, R. San Martin, Le polymorphisme chimique dans le genre Thymus: sa signification taxonomique, Biochemical Systematics and Ecology 5 (1977) 269-272

[2] S. M. Pourmortazavi, S. S. Hajimirsadeghi, Supercritical fluid extraction in plant essential and volatile oil analysis, Journal of Chromatography A 1163 (2007) 2-24.

[3] V. Prakash, Leafy Spices, CRC Press. Boca Raton, USA, 1990, p. 99.

[4] B. D. Mookherjee, R. A. Wilson, R. W. Trenkle, M. J. Zampino, K. P. Sands, Flavor chemistry: trends and developments, ACS Symposium Series. Washington, 1989, p.176.

[5] J. Ferley, N. Poutignat, Y. Azzopard, F. Balducci, Aromathérapie prévantive des surinfections chez les bronchiteux chroniques: evaluation stastique en milieu institutionel: control placebo, Phytotherapy 24 (1988) 8.

[6] M. Höferl, G. Buchbauer, L. Jirovetz, E. Schmidt, A. Stoyanova, Z. Denkova, A. Slavchev, M. Geissler, Correlation of antimicrobial activities of various essential oils and their main aromatic volatile constituents, Journal of Essential Oil Research 21 (2009) 459-63.

[7] K. M. Soliman, R. I. Badeaa, Effect of oil extracted from some medicinal plants on different mycotoxigenic fungi, Food and Chemical Toxicology 40 (2002) 1669-1675.

[8] P. C. Braga, M. Dal Sasso, M. Culici, T. Bianchi, L. Bordoni, L. Marabini, Anti-inflammatory activity of thymol: inhibitory effect on the release of human neutrophil elastase, Pharmacology 77 (2006) 130-136.

[9] H. Tian, D. M. Lai, Analysis on the volatile oil in Origanum vulgare, Journal of Chinese Medicinal Materials 29 (2006) 920-921

[10] M. R. García-Risco, G. Vicente, G. Reglero, T. Fornari, Fractionation of thyme (Thymus vulgaris L.) by supercritical fluid extraction and chromatography, The Journal of Supercritical Fluids 55 (2011) 949-954.

[11] J. D. Thompson, J-C. Chalchat, A. Michet, Y. B. Linhart, B. Ehlers, Qualitative and quantitative variation in monoterpene co-occurrence and composition in the essential oil of Thymus vulgaris chemotypes, Journal of Chemical Ecology 29 (2003) 859-880.

[12] C. Tschiggerl, F. Bucar, Influence of saponin plants on the volatile fraction of thyme in herbal teas, Fitoterapia 82 (2011) 903-910.

[13] M. Moldao-Martins, A. Palavra, M. L. Beirao da Costa, M. G. Bernardo-Gil, Supercritical $\mathrm{CO}_{2}$ extraction of Thymus zygis L. subsp. sylvestris aroma, Journal of Supercritical Fluids 18 (2000) 25-34.

[14] G. Sacchetti, S. Maietti, M. Muzzoli, M. Scaglianti, S. Manfredini, M. Radice, R. Bruni, Comparative evaluation of 11 essential oils of different origin as functional antioxidants, antiradicals and antimicrobials in foods, Food Chemistry 91 (2005) 621-632.

[15] M. Herrero, A. Cifuentes, E. Ibañez, Sub- and supercritical fluid extraction of functional ingredients from different natural sources: plants, food-by-products, algae and microalgae, Food Chemistry, 98 (2006) 136-148.

[16] R. Carabias Martínez, E. Rodríguez Gonzalo, P. Revilla Ruiz, J. Hernández Méndez, Pressurized liquid extraction in the analysis of food and biological samples, Journal of Chromatography A 1089 (2005) 1-17.

[17] L. Gamiz-Gracia, M. D. L. de Castro, Continuous subcritical water extraction of medicinal plant essential oil: comparison with conventional techniques, Talanta 51 (2000) 1179-1185.

[18] M. Z. Ozel, F. Gogus, A. C. Lewis, Subcritical water extraction of essential oils from Thymbra spicata, Food Chemistry 82 (2003) 381-386.

[19] F. J. Eller, S. L. Taylor, Pressurized fluids for extraction of cedarwood oil from Juniperus virginianna, Journal of Agricultural and Food Chemistry 52 (2004) 2335-2338.

[20] M. H. Eikani, F. Golmohammad, S. Rowshanzamir, Subcritical water extraction of essential oils from coriander seeds (Coriandrum sativum L.), Journal of Food Engineering 80 (2007) 735-740.

[21] B. Benthin, H. Danz, M. Hamburguer, Pressurized liquid extraction of medicinal plants, Journal of Chromatography A 837 (1999) 211-219.

[22] A. L. Dawidowicz, E. Rado, D. Wianowska, M. Mardarowicz, J. Gawdzik, Application of PLE for the determination of essential oil components from Thymus vulgaris L., Talanta 76 (2008) 878-884.

[23] A. L. Dawidowicz, E. Rado, D. Wianowska, Static and dynamic superheated water extraction of essential oil components from Thymus vulgaris L., Journal of Separation Science 32 (2009) 3034-3042.

[24] B. K. Ishida, M. H. Chapman, Carotenoid extraction from plants using a novel, environmentally friendly solvent, Journal of Agricultural and Food Chemistry 57 (2009) 1051-1059. 
[25] I. F. Strati, V. Oreopoulou, Effect of extraction parameters on the carotenoid recovery from tomato waste, International Journal of Food Science and Technology, 46 (2011) 23-29.

[26] E. J. Hernández, P. Luna, R. P. Stateva, V. Najdanovic-Visak, G. Reglero, T. Fornari, Liquid-liquid phase transition of mixtures comprising squalene, olive oil, and ethyl lactate: application to recover squalene from oil deodorizer distillates, Journal of Chemical and Engineering Data 56 (2011) 2148-2152.

[27] G. Vicente, A. Paiva, T. Fornari, V. Najdanovic-Visak, Liquid-liquid equilibria for separation of tocopherol from olive oil using ethyl lactate, Chemical Engineering Journal 172 (2011) 879-884.

[28] M. Golmakani, J. A. Mendiola, K. Rezaei, E. Ibáñez, Expanded ethanol with $\mathrm{CO}_{2}$ and pressurized ethyl lactate to obtain fractions enriched in $\mathrm{\gamma}$-linolenic acid from Arthrospira platensis (Spirulina), The Journal of Supercritical Fluids 62 (2012) 109-115.

[29] D. Villanueva Bermejo, P. Luna, M. S. Manic, V. Najdanovic-Visak, T. Fornari, Extraction of caffeine from natural matter using a bio-renewable agrochemical solvent, Food and Bioproducts Processing (in press)

[30] M. S. Manic, D. Villanueva, T. Fornari, A. J. Queimada, E. A. Macedo, V. Najdanovic-Visak, Solubilities of highvalue compounds in ethyl lactate: measurements and modelling, The Journal of Chemical Termodynamics 48 (2012) 93-100.

[31] M. Virot, V. Tomao, C. Ginies, F. Visinoni, F. Chemat, Green procedure with a green solvent for fats and oils determination microwave-integrated Soxhlet using limonene followed by microwave Clevenger distillation, Journal of Chromatography A 1196-1197 ( 2008) 147-152.

[32] T. Toplisek, R. Gustafson, Cleaning with D-limonene: a substitute for chlorinated solvents?, Precision Cleaning The Magazine of Critical Cleaning Technology (1995) 17-22.

[33] P. K. Mamidipally, S. X. Liu, First approach on rice bran oil extraction using limonene, European Journal of Lipid Science and Technology 106 (2004) 122-125.

[34] Z. Chemat-Djenni, M. A. Ferhat, V. Tomao, F. Chemat, Carotenoid extraction from tomato using a green solvent resulting from orange processing waste, Journal of Essential Oil Bearing Plants 2 (2010) 139-147.

[35] R. Omidbaigi, F. Sefidkon, M. Hejazi, Essential oil composition of Thymus citriodorus L. cultivated in Iran, Flavour and Fragrance Journal 20 (2005) 237-238. 